\title{
Investigation of the Nonlinear Electromagnetic Energy Harvesters From Hand Shaking
}

\author{
Huicong Liu, Member, IEEE, Sudeep Gudla, Faezeh Arab Hassani, Chun Huat Heng, Senior Member, IEEE, \\ Yong Lian, Fellow, IEEE, and Chengkuo Lee, Member, IEEE
}

\begin{abstract}
This paper presents the design, modeling, and optimization of an electromagnetic energy harvesting (EMEH) device with various tube length and winding coil width. The nonlinear magnetic-spring configuration is employed for generating sufficient power from hand shaking of irregular and low-frequency vibrations. Based on the modeling and simulation, longer tube length of the EMEH device results in lower resonant frequency and stronger nonlinearity of the system and thus is more efficient for low-frequency harvesting. From the hand shaking test, it is found that a longer tube length and a shorter winding coil width could induce a higher power generation. The optimized device of tube length of $66 \mathrm{~mm}$ and winding coil width of $10 \mathrm{~mm}$ has achieved maximum power outputs of $568.66 \mu \mathrm{W}$ at the hand shaking acceleration of $1 \mathrm{~g}$ and frequency of $6.7 \mathrm{~Hz}$, which corresponds to the power density of $90.67 \mu \mathrm{W} / \mathrm{cm}^{3}$. Further improvement of the device has been achieved by increasing the coil length to $40 \mathrm{~m}$. This device provides maximum power outputs of $825.36 \mu \mathrm{W}$ at the hand shaking acceleration of $1.56 \mathrm{~g}$ and frequency of $6.7 \mathrm{~Hz}$. This paper demonstrates a feasible design of nonlinear EMEH device with impressive output performance from hand shaking.
\end{abstract}

Index Terms-Electromagnetic energy harvester (EMEH), nonlinear, magnetic-spring, hand shaking.

\section{INTRODUCTION}

$\mathbf{T}$ HE concept of vibrational energy harvesting has gained much attention in recent years because of the rapid development on microelectronic devices and systems with low power consumption. A particular motivating scenario is the self-powered wireless sensor network for body and structure health monitoring [1]-[4]. The requirements for an energy

Manuscript received October 12, 2014; revised November 2, 2014; accepted November 12, 2014. Date of publication December 2, 2014; date of current version February 10, 2015. This work was supported in part by the NRF-CRP001-057 Program Project entitled Self-powered Body Sensor Network for Disease Management and Prevention-Oriented Healthcare under Grant R-263-000-A27-281, in part by the Faculty Research Committee under Grant R-263-000-692-112 through the National University of Singapore, Singapore, and in part by the Foundation Research Project of Jiangsu Province under Grant BK20140335. The associate editor coordinating the review of this paper and approving it for publication was Prof. Zeynep Celik-Butler.

H. Liu was with the Department of Electrical and Computer Engineering, National University of Singapore, Singapore 119077. She is now with the Jiangsu Provincial Key Laboratory, Advanced Robotics and Collaborative Innovation Center of Suzhou Nano Science and Technology, Soochow University, Suzhou 215021, China (e-mail: hcliu078@suda.edu.cn).

S. Gudla, F. A. Hassani, C. H. Heng, Y. Lian, and C. Lee are with the Department of Electrical and Computer Engineering, National University of Singapore, Singapore 119077 (e-mail: gsudeep91@yahoo.co.in; elefah@nus.edu.sg; elehch@nus.edu.sg; eleliany@nus.edu.sg; elelc@nus. edu.sg).

Color versions of one or more of the figures in this paper are available online at http://ieeexplore.ieee.org.

Digital Object Identifier 10.1109/JSEN.2014.2375354 harvester are high power efficiency, high durability, and wide operating frequency range. Among the reported vibrational energy harvesters using electromagnetic [5]-[8], electrostatic [9]-[11] and piezoelectric [12]-[15] energy conversion transducers, most if not all of the devices have been characterized by using swept-sine vibration shaker at the laboratory. Thus they may focus on the power generation and vibration behavior of linear oscillators in response to harmonic excitations without considering the irregular vibration frequencies occurring in practical applications.

Nevertheless, some research groups have made the attempts to implement vibrational energy harvesters to the real environment or conducted their measurement under condition close to potential applications. For example, the harvester devices have been tested on engine block of a car [16], different bridge locations [17], human shoes [18] and pocket [19], [20]. Comparing to vibration sources induced by machines and buildings, energy harvesting from human motions are particularly challenging due to the low frequency range $(<10 \mathrm{~Hz})$, and random or even unpredictable vibration pattern. As a result, the most common linear mass-spring-damper systems with narrow frequency range are poorly suitable for energy harvesting from human motions because the output power of a linear harvester drops dramatically under off-resonance conditions [21]. This problem can be overcome by using frequency wideband mechanisms, such as harvester array [22], [23], mechanical stoppers [24]-[26], nonlinear springs [27], [28], frequency tunable mechanisms [29]-[32] and multi-frequency harvesters [33]-[36]. However, most of the reported wideband harvesters operate at relatively high frequencies. In order to achieve low resonant frequency to match with the vibration frequency associated with human motions, i.e. less than $10 \mathrm{~Hz}$, a very compliant spring structure, which is not only the major root cause of damage, but also requires enough space to permit large mechanical displacement.

Saha et al [37] have successfully demonstrated the possibility of harvesting energy from human walking and slow running by using a nonlinear electromagnetic generator with magneticspring. Such type of nonlinear energy harvester with magneticspring offers many advantages of high output performance, high tunability, less prone to failure, ease of construction, and low cost. Hence, similar prototypes have been reported by several groups from different aspects. A theoretical analysis of the nonlinear Duffing oscillator using magnetic levitation has been investigated by Mann and Sims [38]. Dallago et al [39] have taken into account nonlinear effect and built an 


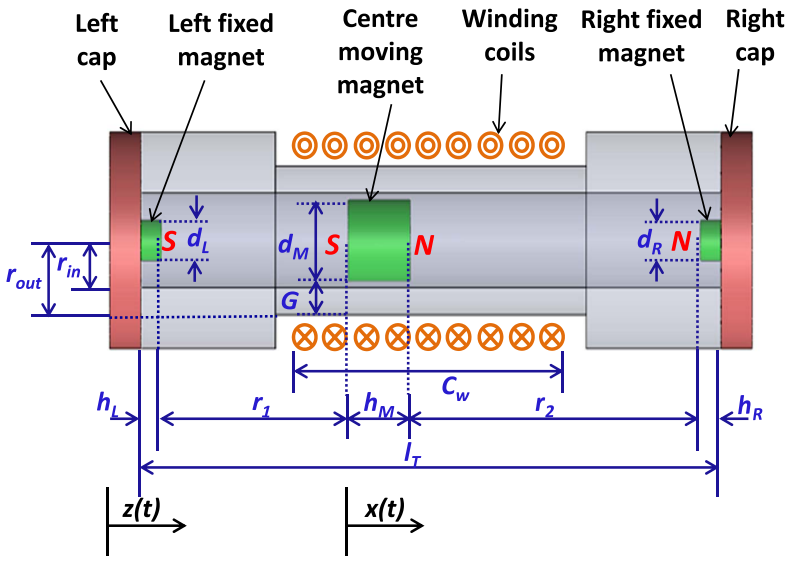

Fig. 1. Schematic diagram of the nonlinear EMEH device.

analytical model of the magnetic-spring based energy harvester. Experimental results have validated that the model is able to predict the voltage performance of the harvester. Foisal et al [40] have presented an array of harvesters with magneticspring and demonstrated the possibility of harvesting energy from multiple frequencies. A similar EMEH using multi-pole magnet has also been studied recently [41] by the same group. On top of these works, it is quite necessary to proceed an optimization of the key parameters such that a feasible design methodology of the magnetic-spring based nonlinear energy harvester could gain more impressive output performance. In this work, we fabricated nonlinear EMEH with various dimension parameters in terms of tube length and winding coil width. The comparison and optimization has been performed based on the modeling and hand shaking test which is aiming at practical applications.

\section{Design And Modeling}

\section{A. Prototype Structure}

A schematic diagram of a nonlinear EMEH with magneticspring is shown in Fig. 1. It is composed of a cylindrical tube made of acrylic glass, two fixed disc magnets of 3-mmdiameter and 2-mm-height, a center moving disc magnet of 6-mm-diameter and 6-mm-height and copper induction coils. The left and right disc magnets are attached respectively on the left and right caps. The three disc magnets are placed in such a way that the same magnetic poles face to each other. Thus the magnetic repulsive force from the left and right magnets serves as magnetic spring and levitates the center disc magnet in the middle of the tube. The copper coils are wrapped at the middle of the outside of the tube with a total coil length $l_{c}$ and winding coil width $C_{w}$. According to Faraday's law of induction, the external ambient vibration causes the center moving magnet to oscillate, which in turn induces change in flux over the winding coil thereby generating electric current in copper coils. To reduce the air damping during the movement of the magnetic mass inside the tube, four distributed throughholes of 3-mm in diameter are drilled on both the left and right caps.

In this work, at the beginning nine different devices are fabricated with three different tube lengths of 46,56
TABLE I

Parameters of the Nonlinear EMEH Device

\begin{tabular}{ll}
\hline \hline \multicolumn{1}{c}{ Symbol } & \\
& \\
\hline Magnetic material & NdFeB $(\mathrm{N} 35)$ \\
Coil material & Copper \\
Housing material & Acrylic \\
Young's modulus $(\mathrm{Pa})$ & $1.53 \times 10^{11}$ \\
Coercive Force $(\mathrm{kA} / \mathrm{m})$ & 860 \\
Residual magnetic flux density $(B r)(\mathrm{T})$ & 1.18 \\
Diameter and height of left magnet $\left(d_{L}, h_{L}\right)(\mathrm{mm})$ & $3 \times 2$ \\
Diameter and height of right magnet $\left(d_{R}, h_{R}\right)(\mathrm{mm})$ & $3 \times 2$ \\
Diameter and height of center magnet $\left(d_{M}, h_{M}\right)(\mathrm{mm})$ & $6 \times 6$ \\
Mass of the moving magnet (inertial mass $)(m)(\mathrm{g})$ & 1.23 \\
Coil resistance $\left(R_{\text {int }}\right)(\Omega)$ & $10,15,20$ \\
Wire diameter $\left(d_{C}\right)(\mathrm{mm})$ & 0.2 \\
Total wire length $\left(l_{C}\right)(\mathrm{m})$ & 20 \\
Coil width $\left(C_{W}\right)(\mathrm{mm})$ & $10,20,30$ \\
Tube length $\left(l_{T}\right)(\mathrm{mm})$ & $46,56,66$ \\
Volume $\left(\mathrm{cm}{ }^{3}\right)$ & $4.37,5.32,6.27$ \\
Inner radius $\left(r_{i n}\right)(\mathrm{mm})$ & 3.5 \\
Outer radius $\left(r_{\text {out }}\right)(\mathrm{mm})$ & 5.5 \\
Spacing between moving magnet and coil $(G)(\mathrm{mm})$ & 2.5 \\
Magnetic flux density $(B)(\mathrm{T})$ & 0.1786 \\
\hline
\end{tabular}

and $66 \mathrm{~mm}$, respectively. Each of them has the same total coil length $l_{c}$ of $20 \mathrm{~m}$ but three different widths of winding coils $C_{w}$ of 10,20 and $30 \mathrm{~mm}$, respectively. The output performances of these devices are compared to obtain the optimized device configuration. Then, by changing two important parameters, i.e. total wired coil length and the coil width, the output performance of the optimized device is improved further. The parameters of the EMEH devices are listed in Table 1 and the device optimization is discussed in later section.

\section{B. Analytical Modeling}

A vibration based energy harvester is essentially a secondorder spring-mass-damper system [21]. The first reference frame in Fig. 1, designated as $z$, describes the motion of tube housing when the input excitation $z(t)=A \cos \Omega t$ is applied in which, $A$ and $\Omega$ represent the motion amplitude and the excitation frequency, respectively. The second reference frame, designated as $x$, represents the motion of center moving magnet. As the model describes in-plane movement, we neglect the acceleration due to gravity g. According to Newton's second law, the equation of motion can be written as [38]:

$$
m \ddot{x}+c_{m}(\dot{x}-\dot{z})+k(x-z)+k_{3}(x-z)^{3}+\alpha i=0
$$

where $m$ is the mass of moving magnet; $c_{m}$ is mechanical damping coefficient; $k$ is linear spring constant; $k_{3}$ is nonlinear spring constant; $x$ is the amplitude of center magnet; $z$ is the amplitude of tube housing; $i$ is electric current; $\alpha=N B l$ is electromagnetic coupling coefficient, where $N$ is number of coil turns and $l$ is the effective coil length; B is the magnetic flux density of a cylindrical magnet, and is given as [42]:

$$
B=\frac{B_{r}}{2}\left(\frac{\left(G+h_{M}\right)}{\sqrt{\left(d_{M} / 2\right)^{2}+\left(G+h_{M}\right)^{2}}}-\frac{G}{\sqrt{\left(d_{M} / 2\right)^{2}+G^{2}}}\right)
$$


(a)

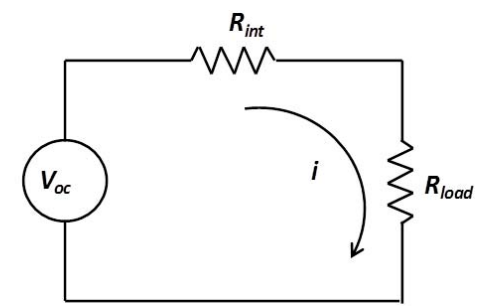

(b)

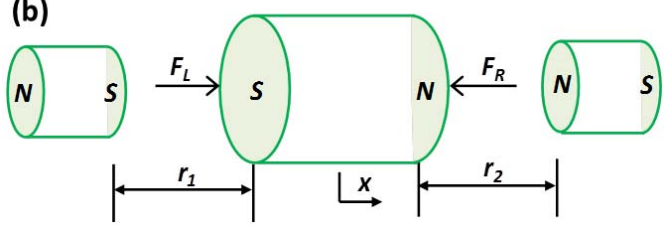

Fig. 2. (a) Circuit diagram of the EMEH device. (b) Magnetic force illustration of the three disc magnets.

where $B_{r}$ is the residual magnetic flux, $G$ is the spacing between the moving magnet and coil, and $h_{M}$ and $d_{M}$ are the height and diameter of the moving mass, respectively.

By applying Kirchhoff's law to the electric circuit in Fig. 2(a), the expression for electric current neglecting coil inductance can be obtained as:

$$
i=\alpha \frac{\dot{x}-\dot{z}}{R_{\text {load }}+R_{\text {int }}}
$$

where $R_{\text {load }}$ and $R_{\text {int }}$ are the load and internal resistances of the device, respectively. By substituting the value of current from Eq. (3) into Eq. (1), we have:

$$
m \ddot{x}+c(\dot{x}-\dot{z})+k(x-z)+k_{3}(x-z)^{3}=0
$$

where $c=c_{m}+c_{e}$ is the total damping coefficient, comprising both mechanical and electrical damping coefficient. The electrical damping coefficient is given by $c_{e}=\frac{\alpha^{2}}{R_{\text {load }}+R_{\text {int }}}$.

As show in Fig. 2(b), the magnetic force between left fixed magnet and right moving magnet is given as [3]:

$$
F_{L}=\frac{\mu_{0} Q_{L} Q_{M}}{4 \pi r_{1}^{2}}
$$

where $r_{1}$ is the distance between left and center magnet poles; the magnetic field intensity is $\mathrm{Q}=\mathrm{H}_{\mathrm{c}} \mathrm{A}, \mathrm{H}_{\mathrm{c}}$ is the coercive force, and A is the pole surface area. Similarly, the magnetic force between right fixed magnet and center moving magnet is given as:

$$
F_{R}=\frac{\mu_{0} Q_{R} Q_{M}}{4 \pi r_{2}^{2}}
$$

where $r_{2}$ is the distance between right and center magnet poles. For the case of in-plane movement of the tube housing, we have the expression for $r_{1}$ and $r_{2}$ as:

$$
r_{1}=r_{2}=\frac{l_{L}-\left(h_{L}+h_{R}+h_{M}\right)}{2}
$$

As the center moving magnet is denoted by distance $x$ as shown in Fig. 2(b), the resultant magnetic force applied to the center moving magnet is obtained as:

$$
F_{\text {res }}=F_{L}-F_{R}=\frac{\mu_{0} Q_{M}}{4 \pi}\left(\frac{Q_{L}}{\left(r_{1}+x\right)^{2}}-\frac{Q_{R}}{\left(r_{2}-x\right)^{2}}\right)
$$

where $F_{\text {res }}$ also represents the magnetic spring restoring force, and is given as:

$$
F_{\text {res }}=k x+k_{3} x^{3}
$$

where $k$ and $k_{3}$ are the linear and nonlinear spring constants, respectively.

By considering the relative displacement between moving magnet and tube housing, we introduce $y=x-z$ and modify the governing equation of motion from Eq. (4) as:

$$
\ddot{y}+2 \zeta \omega m \dot{y}+\omega^{2} y+\beta y^{3}=F_{e} \cos \Omega t
$$

where the damping ratio is $\zeta=\frac{c}{2 \omega m}$, the resonant frequency is $\omega=2 \pi f_{0}=\sqrt{\frac{k}{m}}$, the excitation force per unit mass is $F_{e}=\Omega^{2} A$ and the ratio between nonlinear spring constant and mass of moving magnet is $\beta=\frac{k_{3}}{m}$. The modified frequency response equation by solving Eq. (10) is given as:

$$
\begin{aligned}
\left(\frac{3 \beta}{8 \omega}\right)^{2} a^{6}+\left(\frac{3}{4} \beta\left(1-\frac{\Omega}{\omega}\right)\right) a^{4} & \\
& +\left((\Omega-\omega)^{2}+(\zeta \omega)^{2}\right) a^{2}-\left(\frac{F_{e}}{2 \omega}\right)^{2}=0
\end{aligned}
$$

The detailed derivation can be found in ref [38]. Eq. (11) gives the frequency response amplitude for the relative displacement of the center moving magnet $(|y|=a)$ against the excitation frequency $(\Omega)$, where the relative displacement is given by $\mathrm{y}=\operatorname{acos}(\Omega \mathrm{t}-\Theta)$. Hence, the predicted relative velocity $\dot{y}=-\Omega \operatorname{asin}(\Omega t-\Theta)$ can be obtained, which is more meaningful for the calculation of coil induced voltage as:

$$
\left|V_{\mathrm{oc}}\right|=\alpha|\dot{y}|
$$

By applying Kirchhoff's law to circuit resented in Fig. 2(a) we have:

$$
i=\frac{V_{o c}}{\left(R_{\text {load }}+R_{\text {int }}\right)}
$$

Hence, the maximum averaged power delivered to the load is given by:

$$
P_{\text {avgmax }}=\left(\frac{\alpha \Omega_{\text {max }} a_{\text {max }}}{R_{\text {load }}+R_{\text {int }}}\right)^{2} R_{\text {load }}
$$

where $a_{\max }$ is the maximum amplitude of the frequency response when the system is excited at $\Omega=\Omega_{\max }$. The relationship between them is obtained by setting $\frac{d a}{d \Omega}=0$ in Eq. (11) as:

$$
\Omega_{\max }=\frac{3 \beta}{8 \omega} a_{\max }^{2}+\omega
$$

The expression for $a_{\max }$ is obtained by substituting $\Omega=\Omega_{\max }$ in Eq. (11) as:

$$
a_{\max }=\frac{F_{e}}{2 \zeta \omega^{2}}
$$

By substituting $a_{\max }$ in Eq. (16) into Eq. (15), we have:

$$
\Omega_{\max }=\frac{3 \beta F_{e}^{2}}{32 \omega^{5} \zeta^{2}}+\omega
$$



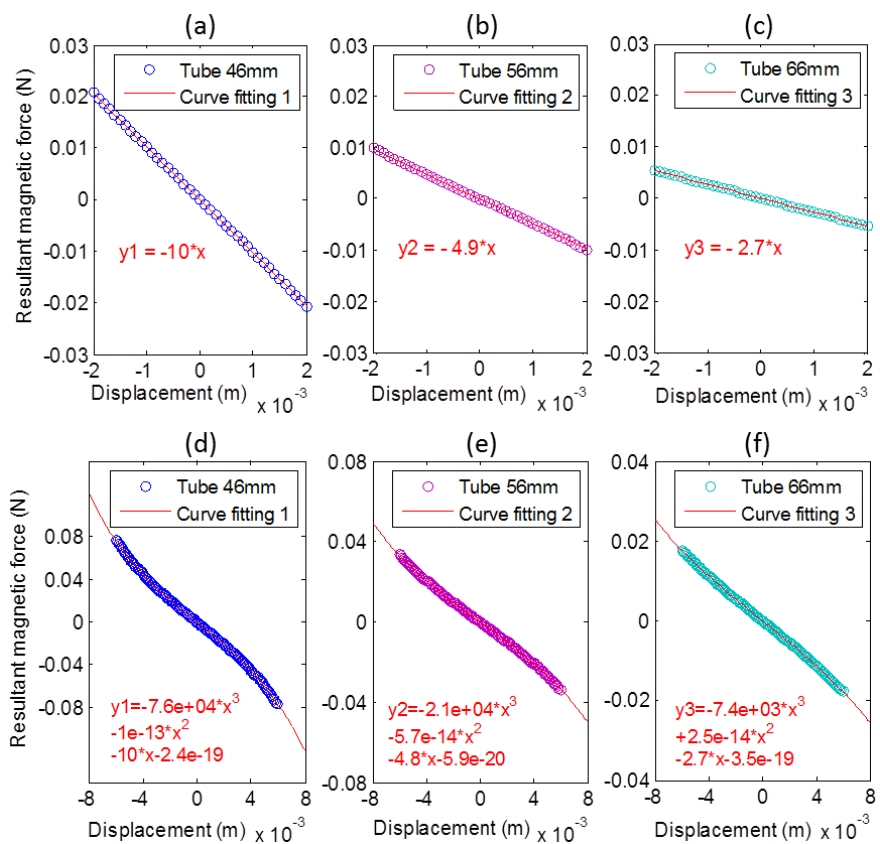

Fig. 3. Simulation of the force-displacement curves for linear region of the tube lengths of: (a) $46 \mathrm{~mm}$, (b) $56 \mathrm{~mm}$, (c) $66 \mathrm{~mm}$ and nonlinear region of the tube lengths of (d) $46 \mathrm{~mm}$, (e) $56 \mathrm{~mm}$, and (f) $66 \mathrm{~mm}$.

TABLE II

Simulated Spring Constant of the Device FOR DIFFERENT TUBE LENGTHS

\begin{tabular}{cccc}
\hline \hline $\begin{array}{c}\text { Tube length } \\
\left(l_{T}\right)(\mathrm{mm})\end{array}$ & $\begin{array}{c}\text { Linear spring } \\
\text { constant }(k) \\
(\mathrm{N} / \mathrm{m})\end{array}$ & $\begin{array}{c}\text { Nonlinear spring } \\
\text { constant }\left(k_{3}\right) \\
\left(\mathrm{N} / \mathrm{m}^{3}\right)\end{array}$ & $\begin{array}{c}\text { Resonant } \\
\text { frequency }\left(f_{0}\right)(\mathrm{Hz})\end{array}$ \\
\hline 46 & 10 & $7.6 \times 10^{4}$ & 14.36 \\
56 & 4.9 & $2.1 \times 10^{4}$ & 10.05 \\
66 & 2.7 & $7.4 \times 10^{3}$ & 7.46 \\
\hline
\end{tabular}

Therefore, by substituting the expressions of $\Omega_{\max }$ and $a_{\max }$ into Eq. (15), the maximum averaged power can be expressed as:

$$
P_{\text {avgmax }}=\left(\alpha F_{e} \frac{3 F_{e}^{2} \beta+32 \zeta^{2} \omega^{2}}{64 \zeta^{3} \omega^{7}\left(R_{\text {int }}+R_{\text {load }}\right)}\right)^{2} R_{\text {load }}
$$

\section{Simulation}

For the nonlinear energy harvester with magnetic spring, the resultant force applied to the center moving magnet is expressed by Eq. (8), by which the force-displacement relationship can be obtained. For different tube lengths of 46, 56 and $66 \mathrm{~mm}$, the magnetic resultant forces against displacements are shown in Fig. 3. By curve fitting in MATLAB, the linear and nonlinear spring constants for different tube lengths can be estimated from the linear region ( -2 to $2 \mathrm{~mm}$ ) in Figs. 3(a)-(c) and the nonlinear region $(-6$ to $6 \mathrm{~mm})$ in Figs. 3(d)-(f). The resonant frequency can be obtained from the linear spring constant. The estimated parameters are listed in Table 2. In the case that the tube length increases, the linear spring constant as well as the resonant frequency decreases. Thus it is preferable condition for the harvesting energy from hand shaking of low frequency vibrations.

The open circuit voltage response can be obtained by executing Eqs. (11) and (12) using MATLAB. The device

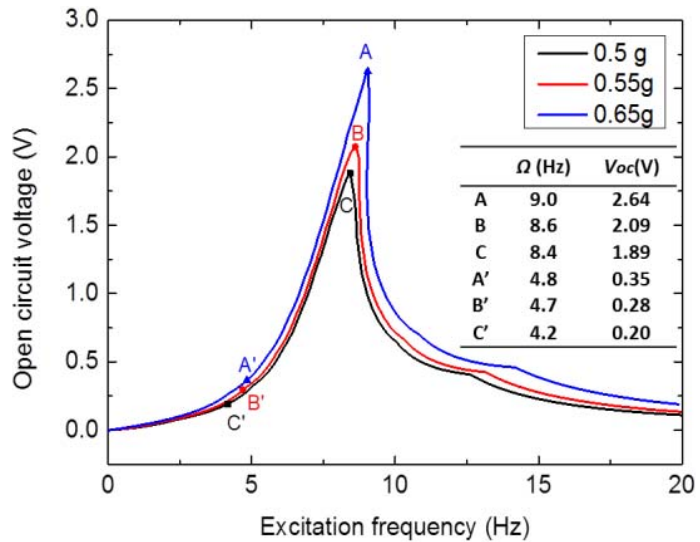

Fig. 4. Simulation of open circuit voltage response of the optimized EMEH device for applied accelerations of: (a) $0.5 \mathrm{~g}$; (b) $0.55 \mathrm{~g}$; and (c) $0.65 \mathrm{~g}$.

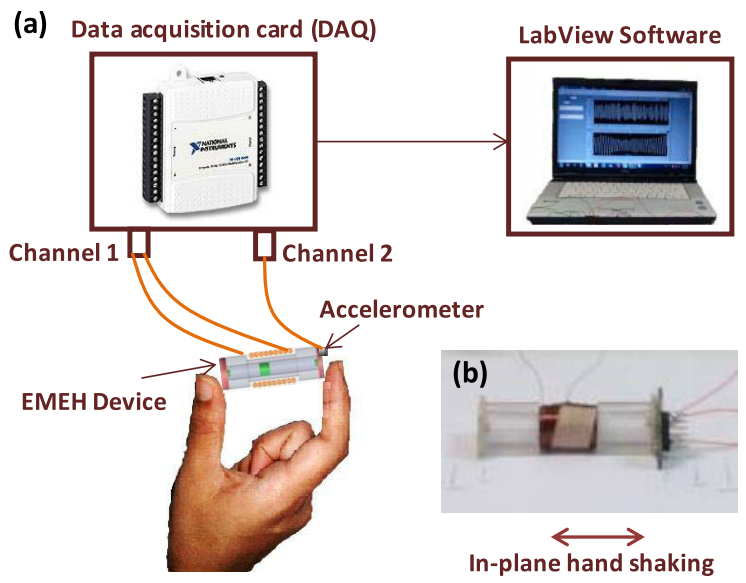

Fig. 5. (a) Schematics diagram of handshaking test setup. (b) Photograph of the EMEH device for in-plane handshaking test.

with tube length of $66 \mathrm{~mm}$ and winding coil width of $10 \mathrm{~mm}$ are used in the simulation and the damping ratio $(\zeta)$ is assumed to be 0.1 . Fig. 4 shows the open circuit voltage against excitation frequency at different accelerations of $0.5 \mathrm{~g}$, $0.55 \mathrm{~g}$ and $0.65 \mathrm{~g}$, where the nonlinear response effect due to the nonlinear magnetic spring force is observed. The open circuit voltages reach their maxima of $1.89,2.09$ and $2.64 \mathrm{~V}$ at the shifted resonant frequencies of $8.4,8.6$ and $9.0 \mathrm{~Hz}$, respectively for the excitation accelerations of $0.5 \mathrm{~g}, 0.55 \mathrm{~g}$ and $0.65 \mathrm{~g}$, respectively. From this point of view, the nonlinearity of the EMEH with magnetic-spring is strengthened as the input acceleration increases.

\section{EXPERIMENTS AND DISCUSSION}

The experimental setup for handshaking test of the EMEH device is shown in Fig. 5. The acceleration magnitude and frequency of the hand shaking is measured by a small and low power accelerometer from Analog Device (ADXL325). A data acquisition (DAQ) card of NI USB-6525 is used to collect signal outputs from the harvester device and accelerometer. The data collected from the DAQ card is processed and displayed in the LabView software. The signal output of the accelerometer is then processed in Matlab by performing FFT (Fast Fourier transform) to convert into frequency domain thereby obtaining value of applied acceleration and frequency. 


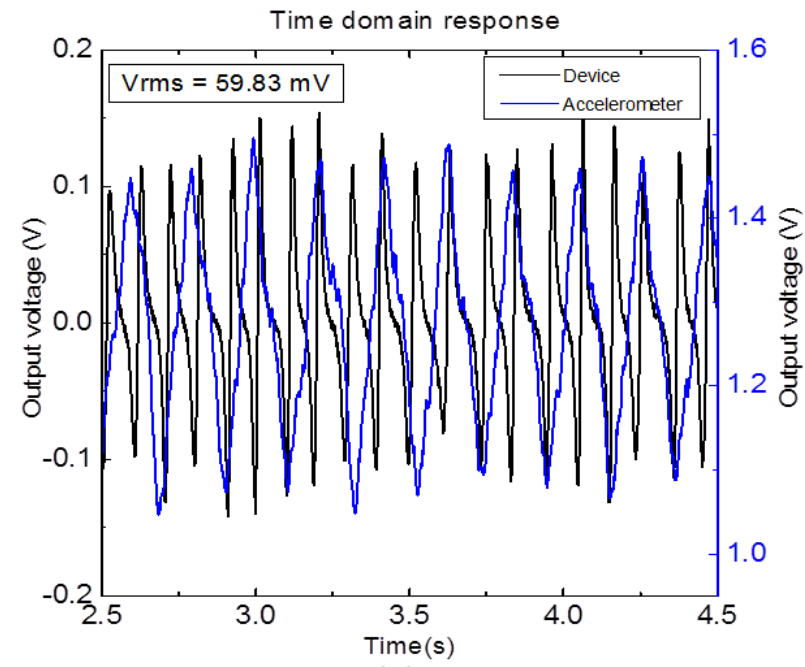

(a)

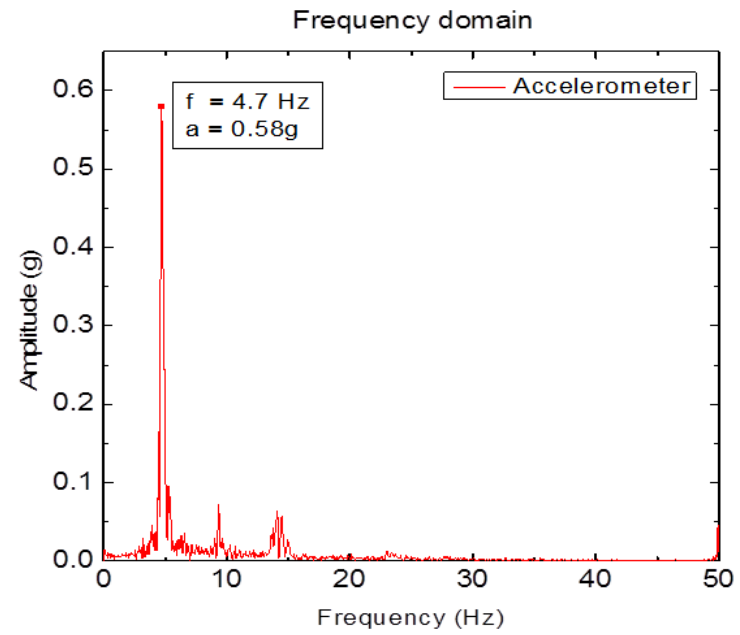

(b)

Fig. 6. (a) Time domain and (b) frequency domain characteristics for tube

\section{A. Device Optimization}

Nine different devices with three tube lengths of 46,56 and $66 \mathrm{~mm}$, while each with winding coil widths of 10,20 and $30 \mathrm{~mm}$, are prepared. There are two categories of comparison in the experiment: (a) varying winding coil width while keeping the tube length constant; and (b) varying tube length while keeping the winding coil width constant. To ensure the comparability and stability of the results, all the nine devices are tested by in-plane hand shaking of about $1 \mathrm{~cm}$ displacement. In the experiment, a relatively constant acceleration of $0.45-0.6 \mathrm{~g}$ and shaking frequency of $4.5-4.8 \mathrm{~Hz}$ are maintained. A load resistance of $10 \Omega$ which matches with the internal coil resistance is connected to gain the maximum power transfer. The time domain characteristics depicted in Fig.6 consists of both EMEH device and accelerometer characteristics obtained from DAQ card. The output root mean square (RMS) voltage is obtained from time domain characteristics of EMEH device and hence we obtain output power delivered to load. Fig. 6 shows the time domain and frequency domain characteristics for tube length of $66 \mathrm{~mm}$ and coil width of $10 \mathrm{~mm}$. Thus we obtain the output for nine different device configurations listed in Table 3 and the comparison for output

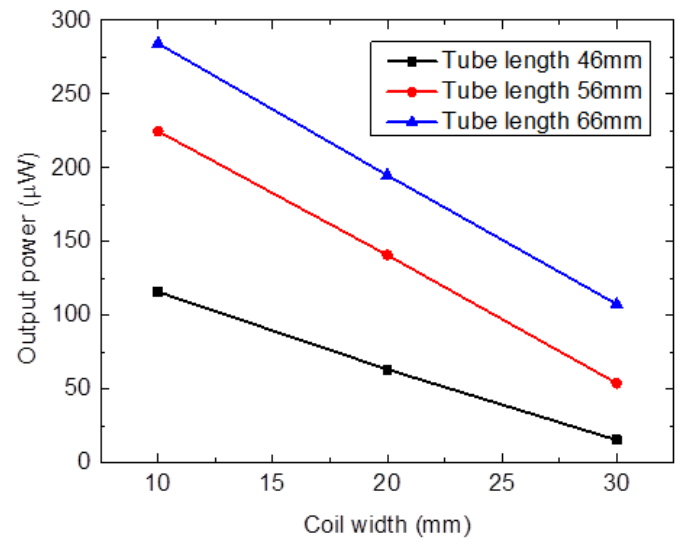

Fig. 7. Comparison of the nine nonlinear EMEH devices with various tube lengths and winding coil widths.

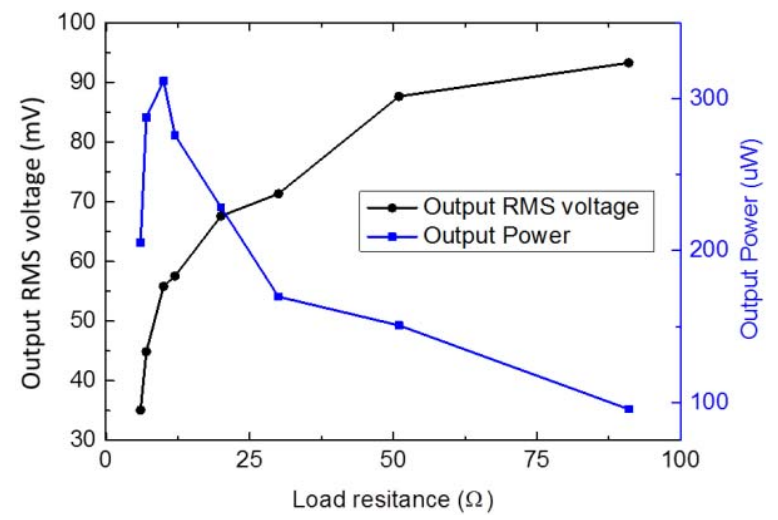

Fig. 8. RMS voltage and output power against load resistance of the optimized device.

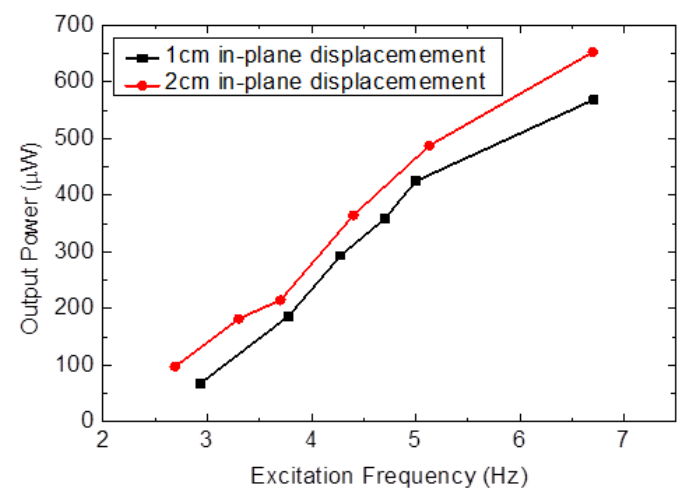

Fig. 9. Output power against excitation frequency of the optimized device for in-plane displacements of 1 and $2 \mathrm{~cm}$.

power delivered to the load for different device configuration is shown in Fig. 7.

For the first comparison with a constant tube length of $46 \mathrm{~mm}$, as the winding coil width increases from 10, 20 to $30 \mathrm{~mm}$, the power delivered to the load decreases from 115.9, 63.25 to $15.4 \mu \mathrm{W}$, respectively. The similar trends have been observed for the tube lengths of 56 and $66 \mathrm{~mm}$. This is because when the magnet enters the winding coil, there is an increasing magnetic flux linkage which produces positive voltage through the coil. When the magnet is completely enclosed by the winding coil, the total flux linkage through the coil is 
TABLE III

Comparison of the Output Performance of Nine Nonlinear EMEH Devices

\begin{tabular}{ccccccc}
\hline \hline $\begin{array}{c}\text { Tube length } \\
(\mathrm{mm})\end{array}$ & $\begin{array}{c}\text { Coil width } \\
(\mathrm{mm})\end{array}$ & $\begin{array}{c}\text { Shaking } \\
\text { acceleration }(\mathrm{g})\end{array}$ & $\begin{array}{c}\text { Shaking frequency } \\
(\mathrm{Hz})\end{array}$ & $\begin{array}{c}\text { RMS voltage } \\
(\mathrm{mV})\end{array}$ & $\begin{array}{c}\text { Power } \\
(\mu \mathrm{W})\end{array}$ & $\begin{array}{c}\text { Power density } \\
\left(\mu \mathrm{W} / \mathrm{cm}^{3}\right)\end{array}$ \\
\hline \multirow{3}{*}{46} & 10 & 0.59 & 4.5 & 34.05 & 115.9 & 26.51 \\
& 20 & 0.59 & 4.8 & 25.15 & 63.25 & 14.47 \\
& 30 & 0.6 & 4.6 & 12.41 & 15.4 & 3.52 \\
\hline \multirow{3}{*}{56} & 10 & 0.45 & 4.4 & 47.41 & 224.77 & 42.25 \\
& 20 & 0.6 & 4.5 & 37.52 & 140.77 & 26.45 \\
& 30 & 0.45 & 4.5 & 23.23 & 53.96 & 10.14 \\
\hline & 10 & 0.54 & 4.5 & 53.13 & 284.28 & 45.34 \\
& 20 & 0.52 & 4.7 & 44.16 & 194.81 & 31.06 \\
& 30 & 0.46 & 4.5 & 32.79 & 107.52 & 17.14 \\
\hline
\end{tabular}

TABLE IV

Comparison of the Simulated and EXPERIMENTAL Results of the Optimized EMEH Device

\begin{tabular}{cccccr}
\hline \hline \multicolumn{2}{c}{ Shaking acceleration $(\mathrm{g})$} & \multicolumn{2}{c}{ Shaking frequency $(\mathrm{Hz})$} & \multicolumn{2}{c}{ Open circuit voltage $(\mathrm{V})$} \\
\hline Simulated & Experimental & Simulated & Experimental & Simulated & Experimental \\
\hline 0.5 & 0.51 & 4.2 & 4.2 & 0.20 & 0.25 \\
0.55 & 0.56 & 4.6 & 4.7 & 0.28 & 0.27 \\
0.65 & 0.65 & 4.8 & 4.8 & 0.36 & 0.30 \\
\hline
\end{tabular}

(a)

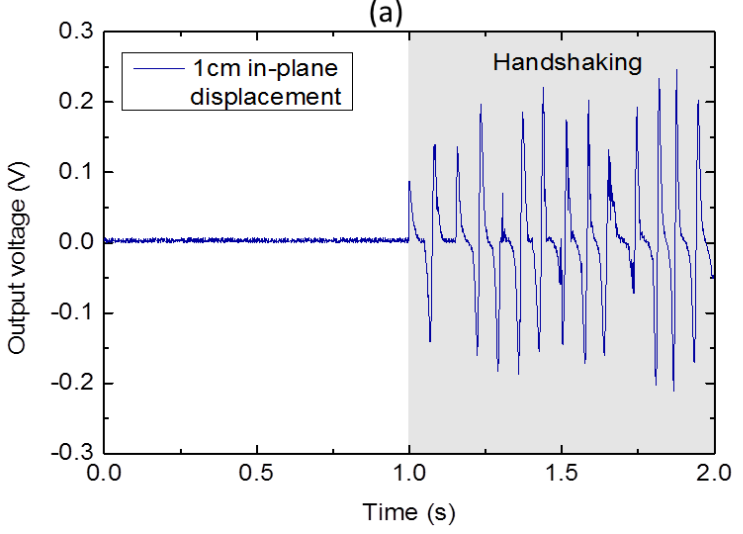

(b)

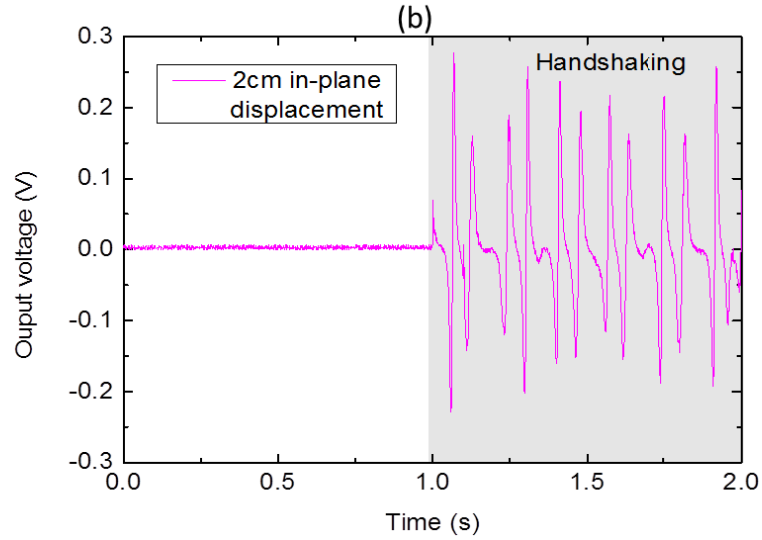

Fig. 10. Time domain voltage waveforms of the optimized device for the in-plane displacement of $1 \mathrm{~cm}$ (a) and $2 \mathrm{~cm}$ (b) at hand shaking frequency of $6.7 \mathrm{~Hz}$.

constant and thus the voltage induced becomes zero. As the magnet leaves the winding coil, there is a decreasing magnetic flux linkage, and the induced voltage is then negative. Clearly, in order to maximize the output voltage using the same total wired length of $20 \mathrm{~m}$, the winding width of the coil should be limited so that the magnetic flux is not completely enclosed by the coil over any significant part of the generation period [43]. Therefore, the EMEH device with shorter winding coil width of $10 \mathrm{~mm}$ performs better and delivers higher power output to the load than the longer winding coil widths of 20 and $30 \mathrm{~mm}$ for the same tube length.

The second comparison considers a constant winding coil width but varying tube length. It is seen in Fig. 7 that at the winding coil width of $10 \mathrm{~mm}$, the power delivered to the load are $115.9,224.7$ and $284.28 \mu \mathrm{W}$ for tube lengths of 46,56 and $66 \mathrm{~mm}$, respectively. The same holds good for winding coil widths of 20 and $30 \mathrm{~mm}$. This is because the linear spring constant decreases with increasing tube length. For a longer tube, the magnetic repulsive force decreases and the inertial mass has a displacement of greater amplitude. For the same external excitation, the displacement will take longer time resulting in lower movement frequency. Hence, the resonant frequency of the system decreases (as described in Table 2) and gets closer to the desired handshaking frequency of about $5 \mathrm{~Hz}$. In addition, larger movement of the inertial mass also implies greater variation of the magnetic field acting on the coil. Thus, the device with longer tube length performs better and delivers higher power to the load. Based on the above comparison, it can be conclude that the optimized configuration among the nine EMEH devices possesses the longest tube length of $66 \mathrm{~mm}$ and the shortest coil width of $10 \mathrm{~mm}$. Hence, the optimized device with the tube length of $66 \mathrm{~mm}$ is selected in the following in-plane hand shaking test.

\section{B. Output Voltage and Power of Optimized Device}

The open circuit voltages of the optimized device generated by hand shaking excited at accelerations of $0.51,0.56$ and $0.65 \mathrm{~g}$ and frequencies of $4.2,4.7$ and $4.8 \mathrm{~Hz}$ are $0.25,0.27$ 
and $0.3 \mathrm{~V}$, respectively. The corresponding simulated open circuit voltages denoted as points $\mathrm{A}^{\prime}, \mathrm{B}^{\prime}$, and $\mathrm{C}^{\prime}$ in Fig. 4 are $0.2,0.28$ and $0.36 \mathrm{~V}$, respectively, at corresponding excitation accelerations of $0.5,0.55$ and $0.65 \mathrm{~g}$ and frequencies of 4.2 , 4.6 and $4.8 \mathrm{~Hz}$. Table 4 shows a comparison between the tested and simulated open circuit voltages. As can be seen, the experimental and modeling results are quite comparable. Figure 8 shows the RMS voltage and power output of the optimized device for different load resistances obtained from handshaking with in-plane displacement of $1 \mathrm{~cm}$ and excitation frequency of $4.5 \mathrm{~Hz}$. The maximum power of $311.7 \mu \mathrm{W}$ is obtained when the load resistance matches with the internal coil resistance of $10 \Omega$.

Figure 9 shows the output power against different excitation frequencies from 2.7 to $6.7 \mathrm{~Hz}$ with respect to the in-plane hand shaking displacements of 1 and $2 \mathrm{~cm}$, respectively, at matched load resistance of $10 \Omega$. As one expected, the output power increases as the excitation acceleration and frequency increase under the same displacement amplitude. The maximum power obtained from the in-plane displacements of 1 and $2 \mathrm{~cm}$ are 568.66 and $652.38 \mu \mathrm{W}$, respectively, at the handshaking limit frequency of $6.7 \mathrm{~Hz}$. The corresponding power densities obtained are 90.67 and $104.02 \mu \mathrm{W} / \mathrm{cm}^{3}$, respectively. The time-domain voltage waveform at corresponding maxima's of displacement 1 and $2 \mathrm{~cm}$ are shown in Fig. 10.

\section{CONCLUDING REMARKS}

In this work, we have designed and fabricated EMEH devices based on nonlinear magnetic-spring configuration. The devices with parameters such as tube length of 46, 56 and $66 \mathrm{~mm}$ and winding coil width of 10, 20 and $30 \mathrm{~mm}$ are investigated via simulation and hand shaking experiment. It is found that a longer tube length reduces the operating frequency of the nonlinear device, and hence more power can be generated when the resonant frequency approaches the driving handshaking frequency. Meanwhile, a limited winding coil width should be considered such that the magnetic flux is not completely enclosed by the coil over the generation period and thus produce more power. In order to make the nonlinear EMEH device more applicable to harvesting irregular human motion of less than $5 \mathrm{~Hz}$, the resonant frequency will be lowered in further study by reducing the magnetic force and optimizing the fixed and movable magnets. The main advantage of the proposed nonlinear EMEH device is its relatively large power and power density of $654.38 \mu \mathrm{W}$ and $104.02 \mu \mathrm{W} / \mathrm{cm}^{3}$, respectively, produced from a very low hand shaking frequency of less than $10 \mathrm{~Hz}$. Therefore, with further improvements, it could be potentially applicable for the self-powered wearable health monitoring devices, such as smart watch.

\section{REFERENCES}

[1] I. F. Akyildiz, W. Su, Y. Sankarasubramaniam, and E. Cayirci, "Wireless sensor networks: A survey," Comput. Netw., vol. 38, no. 4, pp. 393-422, Mar. 2002.

[2] J. P. Lynch, "An overview of wireless structural health monitoring for civil structures," Philosoph. Trans. A, Math., Phys. Eng. Sci., vol. 365, no. 1851, pp. 345-372, Feb. 2007.

[3] S. P. Beeby, M. J. Tudor, and N. M. White, "Energy harvesting vibration sources for microsystems applications," Meas. Sci. Technol., vol. 17, no. 12, pp. R175-R195, 2006.
[4] E. Romero, R. O. Warrington, and M. R. Neuman, "Energy scavenging sources for biomedical sensors," Physiol. Meas., vol. 30, no. 9, pp. R35-R62, Sep. 2009.

[5] E. Sardini and M. Serpelloni, "An efficient electromagnetic power harvesting device for low-frequency applications," Sens. Actuators A, Phys., vol. 172, no. 2, pp. 475-482, 2011.

[6] S. Roundy and E. Takahashi, "A planar electromagnetic energy harvesting transducer using a multi-pole magnetic plate," Sens. Actuators A, Phys., vol. 195, pp. 98-104, Jun. 2013.

[7] R. Morais et al., "Double permanent magnet vibration power generator for smart hip prosthesis," Sens. Actuators A, Phys., vol. 172, no. 1, pp. 259-268, 2011.

[8] S. Kulkarni et al., "Design, fabrication and test of integrated micro-scale vibration-based electromagnetic generator," Sens. Actuators A, Phys., vols. 145-146, pp. 336-342, Jul./Aug. 2008.

[9] B. Yang, C. Lee, R. K. Kotlanka, J. Xie, and S. P. Lim, "A MEMS rotary comb mechanism for harvesting the kinetic energy of planar vibrations," J. Micromech. Microeng., vol. 20, no. 6, p. 065017, 2010.

[10] Y. Suzuki, D. Miki, M. Edamoto, and M. Honzumi, "A MEMS electret generator with electrostatic levitation for vibration-driven energyharvesting applications," J. Micromech. Microeng., vol. 20, no. 10, p. $104002,2010$.

[11] H.-W. Lo and Y.-C. Tai, "Parylene-based electret power generators," J. Micromech. Microeng., vol. 18, no. 10, p. 104006, 2008.

[12] S.-B. Kim, H. Park, S.-H. Kim, H. C. Wikle, J.-H. Park, and D.-J. Kim, "Comparison of MEMS PZT cantilevers based on $d_{31}$ and $d_{33}$ modes for vibration energy harvesting," J. Microelectromech. Syst., vol. 22, no. 1, pp. 26-33, Feb. 2013.

[13] R. Elfrink et al., "Vibration energy harvesting with aluminum nitridebased piezoelectric devices," J. Micromech. Microeng., vol. 19, no. 9 , p. 094005 , Sep. 2009.

[14] H. Liu, C. Lee, T. Kobayashi, C. J. Tay, and C. Quan, "A new S-shaped MEMS PZT cantilever for energy harvesting from low frequency vibrations below $30 \mathrm{~Hz}$," Microsyst. Technol., vol. 18, no. 4, pp. 497-506, 2012.

[15] H. Liu, C. Lee, T. Kobayashi, C. J. Tay, and C. Quan, "Investigation of a MEMS piezoelectric energy harvester system with a frequency-widenedbandwidth mechanism introduced by mechanical stoppers," Smart Mater. Struct., vol. 21, no. 1, p. 035005, 2012.

[16] P. Glynne-Jones, M. J. Tudor, S. P. Beeby, and N. M. White, "An electromagnetic, vibration-powered generator for intelligent sensor systems," Sens. Actuators A, Phys., vol. 110, nos. 1-3, pp. 344-349, 2004.

[17] T. V. Galchev, J. McCullagh, R. L. Peterson, and K. Najafi, "Harvesting traffic-induced vibrations for structural health monitoring of bridges," J. Micromech. Microeng., vol. 21, no. 10, p. 104005, 2011.

[18] J. Kymissis, C. Kendall, J. Paradiso, and N. Gershenfeld, "Parasitic power harvesting in shoes," in Int. Symp. Wearable Comput. Dig. Papers, Oct. 1998, pp. 132-139.

[19] V. Bedekar, J. Oliver, and S. Priya, "Pen harvester for powering a pulse rate sensor," J. Phys. D, Appl. Phys., vol. 42, no. 10, p. 105105 , 2009.

[20] B. J. Bowers and D. P. Arnold, "Spherical, rolling magnet generators for passive energy harvesting from human motion," J. Micromech. Microeng., vol. 19, no. 9, p. 094008, 2009.

[21] C. B. Williams and R. B. Yates, "Analysis of a micro-electric generator for microsystems," Sens. Actuators A, Phys., vol. 52, nos. 1-3, pp. 8-11, 1996.

[22] H. A. Xue, Y.-T. Hu, and Q.-M. Wang, "Broadband piezoelectric energy harvesting devices using multiple bimorphs with different operating frequencies," IEEE Trans. Ultrason., Ferroelectr., Freq. Control, vol. 55, no. 9, pp. 2104-2108, Sep. 2008.

[23] I. Sari, T. Balkan, and H. Kulah, "An electromagnetic micro power generator for wideband environmental vibrations," Sens. Actuators A, Phys., vols. 145-146, pp. 405-413, Jul./Aug. 2008.

[24] M. S. M. Soliman, E. M. Abdel-Rahman, E. F. El-Saadany, and R. R. Mansour, "A wideband vibration-based energy harvester," J. Micromech. Microeng., vol. 18, no. 11, p. 115021, 2008.

[25] H. Liu, C. Lee, T. Kobayashi, C. J. Tay, and C. Quan, "Piezoelectric MEMS-based wideband energy harvesting systems using a frequencyup-conversion cantilever stopper," Sens. Actuators A, Phys., vol. 186, pp. 242-248, Oct. 2012.

[26] H. Liu, C. J. Tay, C. G. Quan, T. Kobayashi, and C. Lee, "Piezoelectric MEMS energy harvester for low-frequency vibrations with wideband operation range and steadily increased output power," J. Microelectromech. Syst., vol. 20, no. 5, pp. 1131-1142, Oct. 2011. 
[27] D. S. Nguyen, E. Halvorsen, G. U. Jensen, and A. Vogl, "Fabrication and characterization of a wideband MEMS energy harvester utilizing nonlinear springs," J. Micromech. Microeng., vol. 20, no. 12, p. 125009 , 2010.

[28] X. Xing, J. Lou, G. M. Yang, O. Obi, C. Driscoll, and N. X. Sun, "Wideband vibration energy harvester with high permeability magnetic material," Appl. Phys. Lett., vol. 95, no. 13, p. 134103, 2009.

[29] D. Zhu, S. Roberts, M. J. Tudor, and S. P. Beeby, "Design and experimental characterization of a tunable vibration-based electromagnetic micro-generator," Sens. Actuators A, Phys., vol. 158, no. 2, pp. 284-293, 2010.

[30] M. Wischke, M. Masur, F. Goldschmidtboeing, and P. Woias, "Electromagnetic vibration harvester with piezoelectrically tunable resonance frequency," J. Micromech. Microeng., vol. 20, no. 3, p. 035025, 2010.

[31] Y.-J. Wang, C.-D. Chen, and C.-K. Sung, "System design of a weightedpendulum-type electromagnetic generator for harvesting energy from a rotating wheel," IEEE/ASME Trans. Mechatronics, vol. 18, no. 2, pp. 754-763, Apr. 2013.

[32] Y.-J. Wang and C.-D. Chen, "Design and jump phenomenon analysis of an eccentric ring energy harvester," Smart Mater. Struct., vol. 22, no. 10, p. 105019, 2013.

[33] N. N. H. Ching, H. Y. Wong, W. J. Li, P. H. W. Leong, and Z. Y. Wen, "A laser-micromachined multi-modal resonating power transducer for wireless sensing systems," Sens. Actuators A, Phys., vols. 97-98, pp. 685-690, Apr. 2002.

[34] B. Yang et al., "Electromagnetic energy harvesting from vibrations of multiple frequencies," J. Micromech. Microeng., vol. 19, no. 3, p. 035001, 2009.

[35] H. Liu, B. W. Soon, N. Wang, C. J. Tay, C. Quan, and C. Lee, "Feasibility study of a 3D vibration-driven electromagnetic MEMS energy harvester with multiple vibration modes," J. Micromech. Microeng., vol. 22, no. 12, p. 125020, 2012.

[36] H. Liu, Y. Qian, and C. Lee, "A multi-frequency vibration-based MEMS electromagnetic energy harvesting device," Sens. Actuators A, Phys., vol. 204, pp. 37-43, Dec. 2013.

[37] C. R. Saha, T. O'Donnell, N. Wang, and P. McCloskey, "Electromagnetic generator for harvesting energy from human motion," Sens. Actuators A, Phys., vol. 147, no. 1, pp. 248-253, 2008.

[38] B. P. Mann and N. D. Sims, "Energy harvesting from the nonlinear oscillations of magnetic levitation," J. Sound Vibrat., vol. 319, nos. 1-2, pp. 515-530, 2009

[39] E. Dallago, M. Marchesi, and G. Venchi, "Analytical model of a vibrating electromagnetic harvester considering nonlinear effects," IEEE Trans. Power Electron., vol. 25, no. 8, pp. 1989-1997, Aug. 2010.

[40] A. R. M. Foisal, C. Hong, and G.-S. Chung, "Multi-frequency electromagnetic energy harvester using a magnetic spring cantilever," Sens. Actuators A, Phys., vol. 182, pp. 106-113, Aug. 2012.

[41] A. Munaz, B.-C. Lee, and G.-S. Chung, "A study of an electromagnetic energy harvester using multi-pole magnet," Sens. Actuators A, Phys. vol. 201, pp. 134-140, Oct. 2013.

[42] T. Zhang, C. Jiang, H. Xu, and J. Mao, "Permanent-magnet longitudinal fields for magnetostrictive devices," J. Appl. Phys., vol. 101, no. 3 , p. 034511, 2007.

[43] M. Duffy and D. Carroll, "Electromagnetic generators for power harvesting," in Proc. IEEE 35th Power Electron. Specialists Conf., vol. 3. Jun. 2004, pp. 2075-2081.

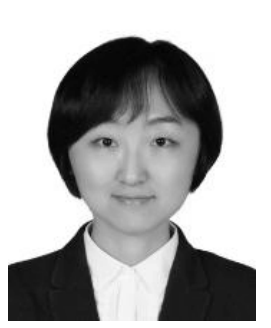

Huicong Liu received the B.Eng. and M.Sc. degrees from the Department of Mechanical Engineering, University of Science and Technology Beijing, Beijing, China, in 2006 and 2008 respectively, and the Ph.D. degree from the Department of Mechanical Engineering, National University of Singapore (NUS), Singapore, in 2013, where she was a Research Fellow with the Department of Electrical and Computer Engineering from 2012 to 2013. She is currently an Associate Professor with the Robotics and Microsystems Center, School of Mechanical and Electric Engineering, Soochow University, Suzhou, China. Her research interests are vibration-based microelectromechanical systems (MEMS)/nanoelectromechanical systems energy harvesters and self-powered MEMS devices and systems.

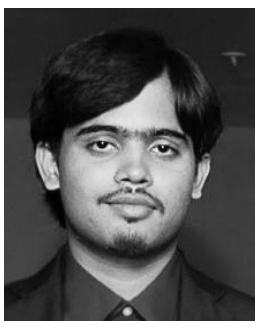

Sudeep Gudla received the B.Tech. degree in electronics and communication engineering from Shanmugha Arts, Science, Technology and Research Academy, Thanjavur, India, in 2012, and the M.Sc. degree in electrical engineering from the National University of Singapore, Singapore, in 2014, where he is currently a Research Engineer with the Department of Electrical and Computer Engineering and is keenly interested in energy harvesting mechanisms for wireless sensor networks and healthcare.

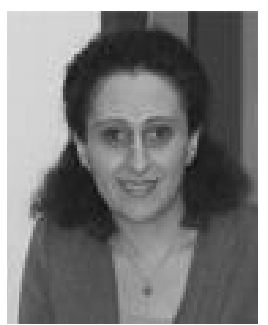

Faezeh Arab Hassani received the bachelor's and M.Sc. degrees from Islamic Azad University, Tehran, Iran, and the University of Tehran, Tehran, in 2004 and 2008, respectively, and the Ph.D. degree from the University of Southampton, Southampton, U.K., in 2012, all in electronic engineering. She joined the Japan Advanced Institute of Science and Technology, Nomi, Japan, for her post-doctoral research fellowship that was awarded by the Japan Society for the Promotion of Science. In 2013, she joined the Department of Electrical and Computer Engineering, National University of Singapore, Singapore, where she is currently a Research Fellow. Her research interests include silicon- and graphene-based nanoelectronics and micro/nanoelectromechanical hybrid devices, sensors, and energy harvesters. She is currently a Research Associate with the University of Sheffield, Sheffield, U.K.

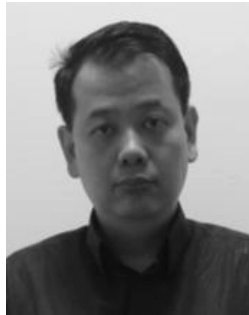

Chun Huat Heng (S'96-M'04-SM'13) received the B.Eng. and M.Eng. degrees from the National University of Singapore (NUS), Singapore, in 1996 and 1999, respectively, and the Ph.D. degree from the University of Illinois at Urbana-Champaign, Champaign, IL, USA, in 2003. He has worked on CMOS integrated circuits involving synthesizer, delay-locked loop, and transceiver circuits. From 2001 to 2004, he was with Wireless Interface Technologies, which was later acquired by Chrontel. Since 2004, he has been with NUS, where he is currently an Associate Professor. He was a recipient of the NUS Annual Teaching Excellence Award in 2008, 2011, and 2013, and was in ATEA Honor Roll in 2014. He was also a recipient of the Faculty Innovative Teaching Award in 2009. He was an Associate Editor of the IEEE TRANSACTIONS ON Circuits And Systems-PART II and is currently a Technical Program Committee Member of the International Solid-State Circuits Conference and the Asian Solid-State Circuits Conference. 


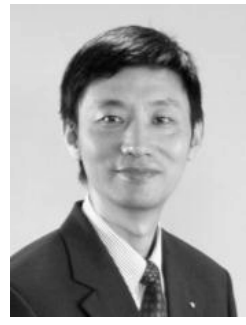

Yong Lian (M'90-SM'99-F'09) received the B.Sc. degree from the College of Economics and Management, Shanghai Jiao Tong University, Shanghai, China, in 1984, and the Ph.D. degree from the Department of Electrical Engineering, National University of Singapore (NUS), Singapore, in 1994. He spent nine years in the industry and joined NUS in 1996. He was appointed as the first Provost's Chair Professor at the Department of Electrical and Computer Engineering, NUS, in 2011. He is the Founder of ClearBridge VitalSigns Pte. Ltd., Singapore, a startup for wireless wearable biomedical devices.

His research interests include biomedical circuits and systems and signal processing. He has received many awards, including the 1996 IEEE CAS Society's Guillemin-Cauer Award for the best paper published in the IEEE TRANSACTIONS ON CIRCUITS AND SYSTEMS-PART II, the 2008 Multimedia Communications Best Paper Award from the IEEE Communications Society for the paper published in the IEEE TRANS ACTIONS ON MULTIMEDIA, the 2011 IES Prestigious Engineering Achievement Award, the 2012 Faculty Research Award, and the 2014 CN Yang Award in Science and Technology for New Immigrant (Singapore). As an Educator, he received the University Annual Teaching Excellent Award, from 2008 to 2010, and many other teaching awards from the Faculty of Engineering. Under his guidance, his students received many awards, including the Best Student Paper Award in ICME 2007, winner of the 47th DAC/ISSCC Student Design Contest in 2010, and the Best Design Award in the A-SSCC 2013 Student Design Contest.

Dr. Lian is the Vice President for Publications of the IEEE Circuits and Systems (CAS) Society, a Steering Committee Member of the IEEE TRANSACTIONS ON BIOMEDICAL CIRCUITS AND SYSTEMS and the IEEE Transactions on Multimedia. He was the Editor-in-Chief of the IEEE TRANSACTIONS ON CIRCUITS AND SySTEMS-PART II: EXPRESS BRIEFs for two terms from 2010 to 2013. He also served as an Associate Editor of the IEEE TRANSACTIONS ON CiRCUITS AND SySTEMSPART I: REgUlar PAPERS, the IEEE TRANSACTIONS ON CIRCUITS AND SYSTEMS-PART II: EXPRESS BRIEFS, the IEEE TRANSACTIONS ON BIOMEDICAL Circuits AND SYstems, and the Journal of Circuits, Systems Signal Processing in the past 15 years, and was the Guest Editor for eight special issues of the IEEE TRANSACTIONS ON CIRCUITS AND SYSTEMSPart I: Regular Papers, the IEEE TRANSACTIONS ON BIOMEDICAL Circuits AND Systems, and the Journal of Circuits, Systems Signal Processing. He was the Vice President of the Asia-Pacific Region of the IEEE CAS Society from 2007 to 2008, an AdComm Member of the IEEE Biometrics Council from 2008 to 2009, the CAS Society Representative to the BioTechnology Council from 2007 to 2009, the Chair of the BioCAS Technical Committee of the IEEE CAS Society from 2007 to 2009, the Chair of the DSP Technical Committee of the IEEE CAS Society from 2010 to 2011, a member of the IEEE Medal for Innovations in Healthcare Technology Committee from 2010 to 2012, and a Distinguished Lecturer of the IEEE CAS Society from 2004 to 2005 . He is the Founder of the International Conference on Green Circuits and Systems, the Asia-Pacific Conference on Postgraduate Research in Microelectronics and Electronics, and the IEEE Biomedical Circuits and Systems Conference. He is a Fellow of the Academy of Engineering Singapore.

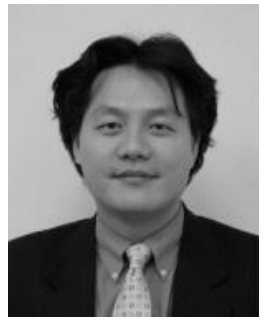

Chengkuo Lee (S'93-M'96) received the M.S. degree in materials science and engineering from National Tsing Hua University, Hsinchu, Taiwan, in 1991, the M.S. degree in industrial and system engineering from Rutgers University, New Brunswick, NJ, USA, in 1993, and the $\mathrm{Ph} . \mathrm{D}$. degree in precision engineering from the University of Tokyo, Tokyo, Japan, in 1996. He was a Foreign Researcher with the Nanometerscale Manufacturing Science Laboratory, Research Center for Advanced Science and Technology, University of Tokyo, from 1993 to 1996 . He was also with the Technical Engineering Laboratory, Advanced Industrial Science and Technology, Ministry of International Trade and Industry of Japan, as a Japan Science and Technology Research Fellow in 1996. Thereafter, he was a Senior Research Staff Member with the Microsystems Laboratory, Industrial Technology Research Institute, Hsinchu. In 1997, he joined Metrodyne Microsystem Corporation, Hsinchu, and established the Microelectromechanical Systems (MEMS) Device Division and the first micromachining laboratory for commercial purposes in Taiwan. He was the Manager of the MEMS Device Division from 1997 to 2000. He was an Adjunct Assistant Professor with the Department of Electrophysics, National Chiao Tung University, Hsinchu, in 1998, and an the Institute of Precision Engineering, National Chung Hsing University, Taichung, Taiwan, from 2001 to 2005. He co-founded Asia Pacific Microsystems, Inc. (APM), Hsinchu, in 2001, and became the Vice President of Research and Development. Until 2005, he was the Vice President of the Optical Communication Business Unit and the Special Assistant to the Chief Executive Officer in charge of international business and technical marketing for MEMS foundry service at APM, Inc., one of the top 30 MEMS manufacturers in the world in 2004. From 2006 to 2009, he was a Senior Member of Technical Staff with the Institute of Microelectronics, Agency for Science, Technology and Research, Singapore. $\mathrm{He}$ is currently an Associate Professor with the Department of Electrical and Computer Engineering, National University of Singapore, Singapore. He co-authored the book entitled Advanced MEMS Packaging (McGraw-Hill, 2010). He has contributed over 230 international conference papers and extended abstracts, 170 peer-reviewed international journal articles, and nine U.S. patents in the fields of MEMS, nanoelectromechanical systems, metamaterials, nanophotonics, and nanotechnology. 